\title{
Case for diagnosis. Ulcerated intradermal nevus simulating Sister Mary Joseph's nodule*
}

\author{
Luísa Groba Bandeira ${ }^{1}$, Juliana Uchiyama ${ }^{1}$, Neusa Yuriko Sakai Valente ${ }^{1}$, Mário Cézar Pires ${ }^{1}$
}

DOI: http:/ / dx.doi.org/10.1590/abd1806-4841.20187324

\section{CASE REPORT}

Male patient, 76 years old, with a history of hypertension, smoking, former alcohol consumption, gout, and stroke, admitted to Neurology two months previously with a new stroke and recent weight loss. Physical examination showed a brownish cerebriform umbilical nodule $2 \mathrm{~cm}$ in diameter surrounded by serous-hematic crust (Figure 1). Patient reported that the lesion was asymptomatic, present for one year, with no recent growth. On dermoscopy, the cerebriform area showed comma-shaped and irregular vessels on a light pink background (Figure 2). The location and dermoscopic clinical features raised the diagnostic hypothesis of Sister Mary Joseph's nodule, and an excisional biopsy was performed. Histopathology showed epidermal atrophy, nevus cells without atypia in the dermis, and preserved deep maturation, interspersed with congested blood vessels (Figures 3 and 4).

\section{DISCUSSION}

Sister Mary Joseph's nodule is a metastasis located in the umbilicus, originating from advanced intraabdominal tumors and with a somber prognosis. Clinically, it presents as a firm, painful, irregular nodule $0.5-2 \mathrm{~cm}$ in diameter. The surface may also present ulceration, necrosis, and purulent or serous secretion. ${ }^{1}$ In dermoscopic examination of this nodule, Mun $\mathrm{JH}$ et al. described vascular polymorphism with serpentine linear and curved linear vessels with whitish and milky-red unstructured areas. Differential diagnosis should include umbilical hernia, malignant or benign primary tumors on the umbilical region, omphalitis, keloids, pyo-

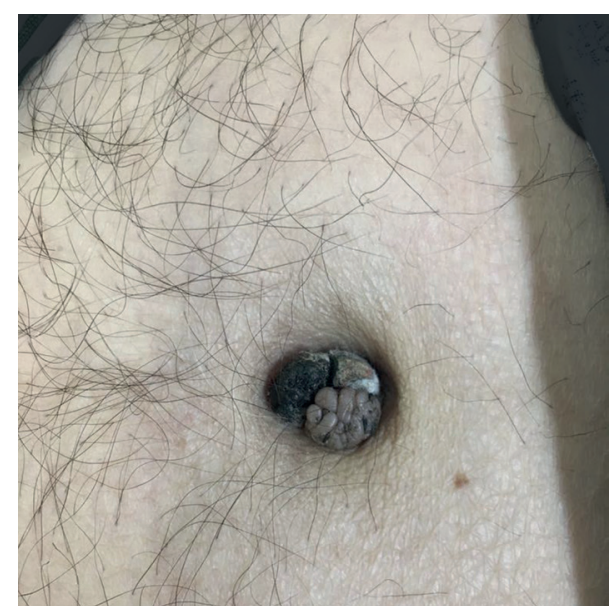

Figure 1: Brownish cerebriform umbilical nodule $2 \mathrm{~cm}$ in diameter with surrounding serous and hematic crust

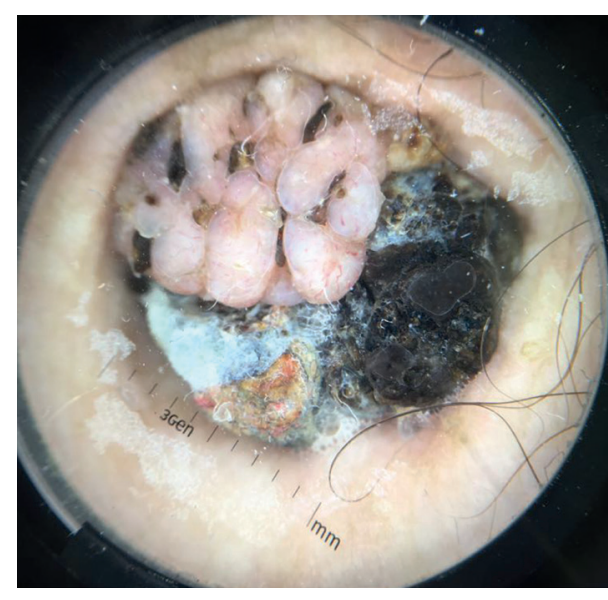

Figure 2: Dermoscopy of the cerebriform area shows comma-shaped and irregular linear vessels on light pink background

Received 06 July 2017

Accepted 07 January 2018.

* Work conducted at Hospital do Servidor Público Estadual, São Paulo (SP), Brazil.

Financial support: None.

Conflict of interest: None.

1 Dermatology Service, Hospital do Servidor Público do Estado de São Paulo, São Paulo (SP), Brazil.

MAILING AdDREsS:

Luísa Groba Bandeira

E-mail: luisagroba@gmail.com 


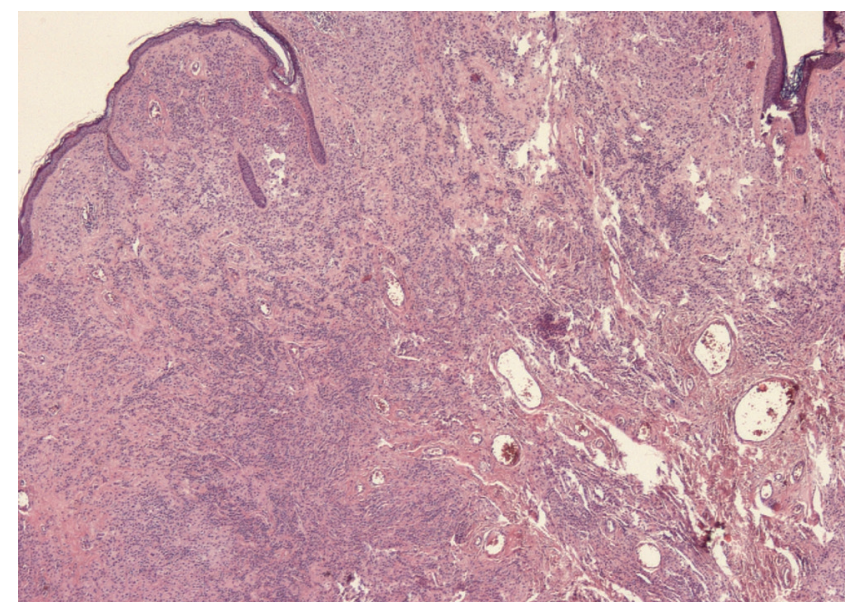

FIGURE 3: Atrophic epidermis, nevus cells without atypia in the dermis, and preserved deep maturation and interspersed congested blood vessels (Hematoxylin \& eosin, x40)

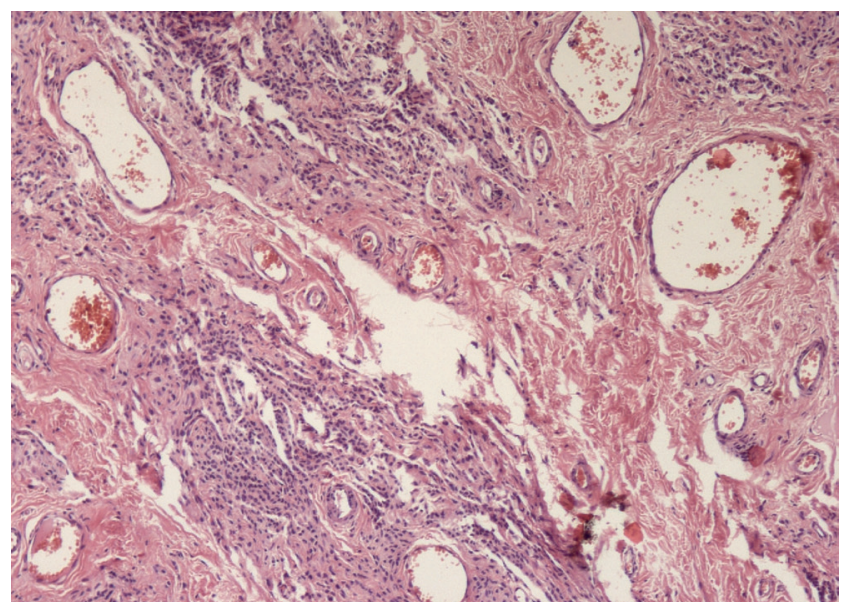

FIGURE 4: Detail: congested vessels in the deep dermis (Hematoxylin $\&$ eosin, $x 100)$ genic granuloma, melanocytic nevus, cutaneous endometriosis, and seborrheic keratosis. ${ }^{1,2}$ Intradermal nevi present as raised lesions, either pigmented or not, which may have a cerebriform appearance. Their most common location is on the face, but they may be found anywhere on the skin surface, although they are uncommon on the palms and soles. On dermoscopy, they present with absence of pigment network and presence of dots and globules. They may also present fine or comma-shaped linear vessels, as in the case de- scribed here. ${ }^{3,4}$ Thus, Sister Mary Joseph's nodule presents similar dermoscopic alterations to those of intradermal nevus. There are comma-shaped or curved linear vessels in both. In addition, there is no description of a specific lesion in Sister Mary Joseph's nodule, which contributed to the difficulty in the differential diagnosis. In these cases, one should suspect metastatic umbilical nodule, and histopathological examination is essential, considering the prognostic importance of this diagnosis, as performed in the case reported here. $\square$

Abstract: We report a case of a 76-year-old patient with a history of recent weight loss and ulcerated umbilical nodular lesion. Initially, we considered the diagnostic hypothesis of Sister Mary Joseph's nodule. However, histopathological evaluation revealed that it was an ulcerated intradermal nevus. We perform a brief review of umbilical nodules.

Keywords: Abdominal neoplasms; Digestive system neoplasms; Nevus; Nevus, intradermal

\section{REFERENCES}

1. Dubreuil A, Dompmartin A, Barjot P, Louvet S, Leroy D. Umbilical metastasis or Sister Mary Joseph's nodule. Int J Dermatol. 1998;37:7-13.

2. Aich RK, Karim R, Chakraborty B, Dasgupta S, Deb AR. Sister Mary Joseph's nodule. Indian J Med Paediatr Oncol. 2008;2:40-3.
3. Mun JH, Kim JM, Ko HC, Kim BS, Kim MB. Dermoscopy of a Sister Mary Joseph nodule. J Am Acad Dermatol. 2013;68:e190-2.

4. Rezze GG, Soares de Sá BC, Neves RI. Dermoscopy: the pattern analysis. An Bras Dermatol. 2006:81:261-8.

AUTHORS'CONTRIBUTIONS

Luísa Groba Bandeira
Elaboração e redação do manuscrito, Obtaining, analyzing and interpreting the data, Critical review of the literature
Juliana Uchiyama
Elaboração e redação do manuscrito, Obtaining, analyzing and interpreting the data, Critical review of the literature
Neusa Yuriko Sakai Valente
Approval of the final version of the manuscript, Effective participation in research orientation, Critical review of the literature, Critical review of the manuscript
Mário Cézar Pires
Approval of the final version of the manuscript, Conception and planning of the study, Critical review of the literature, Critical review of the manuscript

How to cite this article: Bandeira LG, Uchiyama J, Valente NYS, Pires MC. Case for diagnosis. Ulcerated intradermal nevus simulating Sister Mary Joseph's nodule. An Bras Dermatol. 2018;93(6):905-6. 